\title{
Estratégias participativas para a intervençẫo em saúde: relato de experiência no Pet-Saúde graduasus
}

\section{Participatory strategies for health intervention: experience report at Pet-Saúde graduasus}

\section{Estrategias participativas para la intervención sanitaria: informe de la experiencia en el Pet-Saúde graduasus}

\section{Isabel Cristina Belasco", Rafael Andres Patiño"}

Universidade Federal do Sul da Bahia

\section{Resumo}

Este trabalho relata uma experiência de trabalho interdisciplinar desenvolvida por professores, estudantes de um Bacharelado em Saúde, profissionais de saúde, e atores sociais de uma comunidade, no âmbito do Programa de Educação para o Trabalho PET-Saúde GraduaSUS. A primeira parte do projeto se concentrou no diagnóstico participativo da situação de saúde na cidade de Porto Seguro, Brasil, e a partir do qual foram planejadas ações de intervenção junto à comunidade. Especificamente, o texto apresenta uma série de oficinas realizadas com alunos de uma escola da região, que apontaram a violência como um dos principais problemas em seu território. As oficinas foram oferecidas como dispositivo de reflexão, articulação e elaboração de experiências de violência e, ao mesmo tempo, como espaço de reflexão e questionamento de

Doutora em Enfermagem pela Escola de Enfermagem de Ribeirão Preto USP (2005). Professora Adjunta da Universidade Federal do Sul da Bahia, Porto Seguro-Brasil. Correio eletrônico: isabel.belasco@gmail.com https://orcid.org/0000-0001-7763-0826

“ Pós-doutor em Memória Social, pela Universidade Federal do Estado do Rio de Janeiro. Professor adjunto da Universidade Federal do Sul da Bahia, coordenador do grupo de pesquisa Estudos interdicplinares sobre subjetividade, relações de poder e violência, Porto Seguro-Brasil. Correio eletrônico: rafaelpatino@ufsb.edu.br Perfil Orcid: http://orcid.org/0000-0001-64928252, Perfil de Google Acadêmico https://scholar.google.com.br/citations?hl=pt-BR\&user=YpNlylAAAAAJ 
práticas de discriminação e violação de direitos humanos, com as quais os jovens têm contato na sua vida cotidiana. 0 trabalho reafirmou o poder das estratégias participativas de intervenção social para produzir transformações sociais e subjetivas, inclusive em relação aos problemas no campo da saúde.

\section{Palavras chave}

Adolescentes; Metodologias participativas; Violência; Saúde; Território; Intervenção psicossocial; Intervenção em saúde.

\section{Abstract}

This paper relates an interdisciplinary intervention experience developed by professors, students of a Bachelor of Health, health professionals and social actors from a community, within the PET-Saúde GraduaSUS. The first part of the project focused on a participatory diagnosis of the health situation in the city of Porto Seguro, Brazil. Specifically, the text descrives workshops carried out with students from a school of the region, who pointed out violence, as one of the main problems in their territory. The workshops were offered as a strategy for reflection, articulation and elaboration of experiences of violence and, at the same time, as a space for reflection and questioning of practices of discrimination and violation of human rights, experienced by young people in their daily life. The outcomes reaffirmed the power of participatory social intervention strategies to produce social and subjective transformations, including in relation to problems in the health field.

\section{Keywords}

Adolescents; Participatory research; Violence; Health; Territory; Psychosocial intervention; Health intervention.

\section{Resumen}

Este trabajo relata una experiencia de trabajo interdisciplinario desarrollada por profesores, estudiantes de una Licenciatura en salud, profesionales de salud y actores sociales de una comunidad, dentro del Programa de Educación para el Trabajo PET-Salud GraduaSUS. La primera parte del proyecto se concentró en un diagnóstico participativo de la situación de salud en la ciudad de Porto Seguro, Brasil, a partir del cual fueron planeadas acciones de intervención, junto con la comunidad. Específicamente, el texto presenta una serie de talleres realizados con, estudiantes de una escuela de la región, que apuntaron la violencia como uno de los principales problemas de su territorio. Los talleres fueron ofertados como un dispositivo de reflexión, articulación y elaboración de experiencias de violencia y, al mismo tiempo, como un espacio de reflexión y cuestionamiento de prácticas de discriminación y de violación de los derechos humanos, con las que los jóvenes tienen contacto en su cotidianidad. El trabajo reafirmo la potencia de las estrategias intervención social participativas para producir transformaciones sociales y subjetivas, inclusive en relación a problemas el campo de salud.

\section{Palabras clave}

Adolescentes; Metodologías participativas; Violencia; Salud; Territorio; Intervención psicosocial; Intervención en salud. 


\section{Introdução}

O PET-Saúde é um Programa interministerial que, em suas diversas versões, vem contribuindo com o fortalecimento do Sistema Único de Saúde do Brasil (SUS), e com a formação dos graduandos na área da Saúde por meio da parceria Ensino, Serviço e Comunidade (Brasil, 2008). No Município de Porto Seguro, a Universidade Federal do Sul da Bahia, representada por docentes e discentes ligados ao curso de Bacharelado Interdisciplinar em Saúde, desenvolveu ações intersetoriais dentro da proposta do Edital PET-Saúde GraduaSUS, 2015 (Brasil, 2015a).

Nessa versão do Programa, a parceria com a Academia tornou-se mais relevante à medida que, a partir da execução de cada projeto, um dos objetivos foi o aprimoramento da arquitetura curricular dos cursos da área de Saúde, consoante com o Sistema Único de Saúde e a Comunidade atendida pelo mesmo (Brasil, 1990). Em síntese, as ações visam melhorar os processos de ensino-aprendizagem dos futuros profissionais por meio do diálogo com os serviços e as reais necessidades de cada comunidade. A esse respeito, estudos apontam para a potencialidade do PET-Saúde na reorientação da formação e dos serviços em saúde a partir de reflexões e ações sobre problemas concretos dentro dos territórios, e dos equipamentos do SUS (Farias-Santos \& Noro, 2017; de Santana Madruga et al., 2015). Além de visar a melhora na formação dos alunos, o programa também se pauta pela participação ativa da comunidade nos processos de diagnóstico e intervenção, sempre partindo do princípio de que a saúde não é fenômeno exclusivamente biológico, mas que se encontra condicionada social e subjetivamente.

O presente relato refere-se à experiência de um grupo interprofissional composto por dois docentes, um psicólogo e uma enfermeira; doze estudantes, e três profissionais da rede de atenção básica do município, sendo uma enfermeira, uma assistente social e uma zootecnista. Este grupo buscou focalizar suas ações na área de Saúde Coletiva, tendo como público alvo a população do Centro do Município de Porto Seguro (Bahia), no Brasil.

No primeiro ano de atuação foi realizado o Diagnóstico Situacional da saúde no território alvo, processo que foi dividido em dois momentos principais: inicialmente o levantamento do perfil sociodemográfico, epidemiológico e socioambiental utilizando-se da Territorialização em Saúde, e posteriormente a Análise da Situação de Saúde (ASIS) da população adscrita ao território de duas equipes de Saúde da Família, além de um levantamento da configuração e funcionamento dos serviços, a partir das percepções dos usuários e dos profissionais.

Desenvolvido principalmente no campo da geografia, tomamos como referência o conceito de território porque permite reconhecer, as relações de poder que o constituem um determinado contexto social. Adicionalmente, o território é construído historicamente e se configura a partir de objetos de origem técnica e social (Saquet \& Silva, 2008; Santos, 1996). Desse modo, o sis- 
tema de relações que compõe o território pode estar composto por políticas públicas, tecnologias sociais, normas e regulamentos formais; mas também por dinâmicas informais desenvolvidas nos espaços sociais concretos, desigualdades socioeconômicas, práticas sociais etc.

Este trabalho toma como referência a discussão sobre território presente na vasta obra de Milton Santos, a qual trata das questões espaciais/territoriais em saúde de forma ampliada, na tentativa de superação de uma visão de espaço meramente físico, para uma perspectiva que inclui o social, permitindo pensar a saúde enquanto processo de mudança da estrutura espacial, não apenas de forma descritiva. $\mathrm{O}$ autor contribui para a superação de uma visão não histórica $\mathrm{e}$ apensas biologicista, incluindo na compreensão da saúde fatores econômicos, sociais, políticos e culturais, que também são responsáveis por doenças e agravos, o que leva a uma visão de integralidade, que por muitas vezes falta às análises em saúde (Faria \& Bortolozzi, 2009).

Segundo a Lei 8080 de 1990, é objetivo do SUS a identificação e divulgação dos fatores condicionantes e determinantes da saúde, para tanto, os dados coletados devem traduzir a realidade do território com vistas à implementação de ações que busquem a resolução de problemas e formulação de políticas públicas voltadas à melhoria das condições de vida e Saúde da população (Brasil, 1990).

Por este motivo, a análise deve estar orientada pela observação dos problemas, incluindo a busca de dados, a identificação daqueles dados que são relevantes para as problemáticas alvo, assim como a transformação desses dados em informações úteis para sua compreensão e resolução (Brasil, 2015b).

Na tentativa de definir o termo Territorialização em Saúde, faz-se necessário abordar a historicidade do conceito de território, seus significados e apropriação no campo da saúde pública e da saúde coletiva. A saúde pública tem recorrido já há alguns anos a essa estratégia, como ferramenta para mapeamento de eventos de saúde-doença, de equipamentos de saúde e demarcação de áreas de atuação. Existem diferentes usos para o termo Territorialização no sentido teórico, prático e metodológico, destacando sua importância no cenário da reordenação da atenção, da rede de serviços e das práticas sanitárias locais (Gondim \& Monken, 2008, Cardoso Júnior \& Cunha, 2015).

Nesta compreensão, a promoção da saúde não se refere apenas à ausência de doença, mas abrange também os determinantes sociais da saúde, incluindo as condições de vida da população, habitação, saneamento básico, educação, renda, trabalho, alimentação, meio ambiente, lazer, segurança, serviços assistenciais, além de variáveis étnicas e de gênero, entre outras (Universidade Federal do Sul da Bahia [UFSB], 2016). 
Para Buss (2000), a partir de uma concepção ampla do processo saúde-doença e seus determinantes, a promoção de saúde tem como proposta a articulação de saberes técnicos e populares, mobilização de recursos institucionais e comunitários, públicos e privados visando sua implementação.

Na Carta de Otawa redigida a partir da Conferência Mundial de Saúde realizada no ano de 1986, um dos documentos fundadores do conceito atual de promoção de saúde, esse termo está relacionado a um conjunto de valores, entre eles, qualidade de vida, solidariedade, equidade, democracia, cidadania, desenvolvimento, participação e parceria.

Nesse documento, funda-se o conceito que desloca a promoção de saúde do nível individual para o coletivo, ampliando o papel dos determinantes sociais, bem como propondo ações intersetoriais para a sua resolução (Buss, 2000).

Nesse sentido, em uma visão ampliada de saúde, dentre os problemas de abrangência da Vigilância em Saúde, a violência, como fenômeno complexo, é um dos mais relevantes, avaliação confirmada pelos relatórios da Organização Mundial de Saúde (OMS), os quais apontam a violência como uma das principais causas externas de agravos à saúde. (Organização Mundial de Saúde [OMS] 1995; Jorge, 2002)

\section{A violência representa atualmente, um importante desafio para os profissionais do setor da saúde, uma vez que a organização dos seus atendimentos está centrada no modelo biomédico, marcado por uma lógica de relações muito lineares de causa e efeito entre os fenômenos, pouco aproveitável para o problema em questão. (Oliveira et al., 2011, p. 413)}

Nesse sentido, a violência enquanto fenômeno complexo, afeta tanto a saúde individual como coletiva, impactando diretamente a qualidade de vida de pessoas e comunidades, o que gera problemas para o atendimento dos serviços de saúde, e que segundo de Souza Minayo et al. (2018) carece de atuação interdisciplinar, multiprofissional, intersetorial e socialmente engajada.

Segundo o Fórum Brasileiro de Segurança Pública (FBSP) e o Instituto de Pesquisa Econômica Aplicada (IPEA) as taxas de homicídio vêm crescendo nos últimos anos no Brasil.

Nesse país, a violência não se limita aos homicídios por armas de fogo, mas está relacionada a indicadores de desigualdade e suas consequências afetam amplamente a saúde individual e coletiva da população. Por esse motivo, há uma complexa demanda de ações intersetoriais orientadas a intervir sobre essa problemática. Segundo a ONG mexicana Seguridad, Justica y Paz (2020), 10 das 50 cidades com maior taxa de homicídio do mundo estão no Brasil. 
Os jovens estão entre os grupos populacionais mais afetados. Segundo o Atlas da Violência 2018, o homicídio representa 50,3\% entre as causas de morte de homens entre 15 e 29 anos. Ao mesmo tempo, o Índice de Vulnerabilidade Juvenil à Violência indica que o jovem negro tem 2,7 vezes maior risco de ser vítima de homicídio, do que um jovem branco (Brasil, 2017; Instituto de Pesquisa Econômica Aplicada e Fórum Brasileiro de Segurança Pública [IPEA/FBSP], 2018).

O estado da Bahia sofreu um aumento de 104,4\% na taxa de homicídios de negros por 100 mil habitantes entre os anos de 2006 e 2016. A população negra (principalmente homens e jovens), são os principais sujeitos e vítimas da ação letal da polícia (IPEA/FBSP, 2018).

De acordo com o Índice de Vulnerabilidade Juvenil à Violência (2017), a cidade de Porto Seguro-BA é classificada como de Alta vulnerabilidade, ocupando o $44^{\circ}$ lugar entre os municípios com mais de 100.000 habitantes no território nacional. Esta cidade está entre os 123 municípios que respondem a 50\% das mortes violentas no país (IPEA/FBSP, 2018). O município ocupou em 2016 a $14^{\mathrm{a}}$ posição entre os 150 municípios com maiores taxas de homicídio por arma de fogo (Waiselfiz, 2016).

Adicionalmente, os estudos mostram que os profissionais de saúde que trabalham com fenômenos relacionados à violência ou com pessoas que sofreram algum tipo de agressão o desrespeito, são propensos a desenvolverem síndromes e transtornos de saúde que os afetam física e psicologicamente (Santos et al., 2010).

Em consonância com o panorama apresentado, o ingresso no território durante o PET-Saúde permitiu identificar a violência como fenômeno multifacetado, destacado pelas equipes de saúde, dentre as problemáticas que mais afetam a sua cotidianidade.

A partir desse levantamento, evidenciou-se a necessidade de aprofundar o diagnóstico situacional incluindo a perspectiva dos habitantes do território estudado. Tendo em vista ser imprescindível que o diagnóstico situacional se faça a partir da visão dos atores envolvidos. No levantamento dos dados para Análise da Situação de Saúde foram utilizadas ferramentas de diagnóstico participativo junto à equipe e à comunidade, as quais forneceram subsídios importantes para embasar as ações de intervenção que se configuram como objeto específico deste relato.

Quando se pensa em planejamento de ações na área de Saúde dentro do paradigma da Promoção da Saúde, há de se lançar mão de alguns referenciais teóricos que embasem o pensamento e as estratégias a serem utilizadas. Surge o desafio de compreensão da Saúde a partir das significações subjetivas. Por esse motivo a participação dos moradores dos territórios é fundamental para a compreensão das problemáticas. No caso, promover a saúde remete à elaboração de estratégias que garantam, minimamente, a justiça social que está estreitamente ligada com o princípio da equidade, preconizado pela política pública norteadora da Saúde no Brasil (Castro \& Abramovay, 2015; Becker et al., 2004; Souza Romeiro et al., 2020). 
O Planejamento Estratégico Situacional (PES), baseado na obra de Carlos Matus (Matus, 1993) que vem sendo aplicado no planejamento em saúde, parte da concepção metodológica problematizadora, que se vale da identificação coletiva de problemas, buscando explicá-los e superá-los por meio da adequada intervenção no contexto sociopolítico em que eles se apresentam (Teixeira, 2010).

Segundo Matus apud Teixeira (2010) é importante considerar que a condição que expressa a compreensão da realidade de um grupo é sempre situacional, ou seja, está em constante mudança, a partir da interferência de fatores circunstanciais. O termo "situação", definido por Matus, refere-se a um espaço construído socialmente, no qual diferentes papéis são desempenhados e diferentes intervenções podem ser realizadas de acordo com os objetivos dos atores sociais envolvidos.

Para a compreensão dessa realidade, e possibilidade de êxito nas ações pretendidas há de se planejar considerando as interpretações dos atores envolvidos e sua participação no processo para formulação de estratégias eficientes de atuação. Um dos momentos do Planejamento Situacional é o Diagnóstico Situacional, no qual se levanta a realidade e seus problemas mais relevantes.

No projeto desenvolvido, optou-se por utilizar o Diagnóstico Participativo, método que, segundo Castro e Abramovay (2015), é utilizado para levantamento da realidade local. Isto é feito com a participação de lideranças locais, ou qualquer outro integrante de um grupo específico, devendo contemplar os principais problemas do território em todas as áreas (social, econômica, cultural, ambiental, físico-territorial e político-institucional).

\section{Procedimentos metodológicos}

Os procedimentos metodológicos do Diagnóstico Situacional estiveram orientados pelos princípios da Pesquisa-Ação Participante, a qual origina-se a partir confluência de várias escolas críticas de pesquisa social e de pedagogia social: educação popular latino-americana, teorias de Paulo Freire, pedagogia da libertação etc., que têm bases epistemológicas comuns. (Alberich Nistal, 2008).

Este é um tipo de pesquisa associada à transformação social em contextos específicos. Sua origem está intensamente vinculada a processos de desenvolvimento comunitário. Três características a diferenciam de outras perspectivas epistemológicas: construção partilhada com os participantes dos projetos de pesquisa, identificação e priorização dos problemas baseados na comunidade e uma orientação centrada na ação junto à comunidade (Thiollent, 2000; Kemmis \& McTaggart, 2000). Assim, 


\begin{abstract}
A Pesquisa-Ação Participativa se enquadra no que se denomina metodologias implicativas, que supõem a inclusão de negociações e participação plural em processos complexos. Por seus conteúdos, também podem ser denominadas simplesmente como metodologias participativas. (Alberich Nistal, 2008, p. 138)
\end{abstract}

Trata-se de uma estratégia voltada à descrição e resolução de problemas concretos dentro das comunidades participantes. Dessa forma, a Pesquisa-Ação é uma metodologia que combina de forma simultânea a investigação e a intervenção, envolvendo estratégias grupais orientadas a responder com maior eficiência aos problemas da situação, por meio de uma ação transformadora (Thiollent, 2000).

As informações para a análise participativa de dada realidade, podem ser reunidas de várias formas. Conforme Castro e Abravovay (2015), podem ser utilizadas entrevistas semiestruturadas, individuais ou de grupos, técnicas de visualização, observação participativa, análise das tradições culturais e oficinas entre outros. A escolha das técnicas está orientada por um sentido democratizador (Alberich Nistal, 2008).

Neste caso, a experiência relatada com os adolescentes teve três fases. Na primeira foi realizado um diagnóstico da situação de saúde no território usando dados secundários.

A partir do segundo momento do processo, a participação da comunidade (neste caso os jovens), foi fundamental durante o trabalho de diagnóstico e intervenção participativa, dentro do qual a oficina foi a estratégia central empregada durante o processo.

Concebemos as oficinas como práticas sociais e dispositivos discursivos facilitadores para a coconstrução de sentidos sobre fenômenos vivenciados nas relações cotidianas, cujos efeitos não necessariamente respondem aos objetivos originais (Spink, Menegon e Medrado 2014).

As oficinas estão assim,

\begin{abstract}
[...] configuradas como ferramentas ético-politicas privilegiadas, pois propiciam a criação de espaços dialógicos de trocas simbólicas e a coconstrução de outras possibilidades de sentidos acerca das temáticas discutidas, cujos efeitos não se limitam aos usos que os pesquisadores possam fazer desse material, mas também alertam para potenciais transformações nas práticas discursivas geradas naquele contexto, numa fusão inseparável entre o que se convencionou chamar de "coleta de informações e produção de informações. (Spink et al., 2014, p. 34)
\end{abstract}

A utilização dessa estratégia introduz de forma explícita a dimensão ético-política nos processos de pesquisa porque permite evidenciar relações de poder, analisar práticas sociais e põe em jogo a subjetividade, favorecendo a emergência da dimensão emocional dentro da dinâmica grupal.

Desse modo a oficina é um dispositivo multidimensional conformado por elementos diversos, entre eles: sujeitos, repertórios simbólicos, representações, linguagens, técnicas, todos articulados para produzir fazeres coletivos (Ghiso, 1999). 
A primeira oficina esteve pautada por dois momentos: no primeiro os jovens deviam representar, por meio do sociodrama, o que, na opinião deles se configuraria como o maior problema de saúde do seu território. Participaram desta e das seguintes fases 20 estudantes entre 14 e 18 anos de idade, de ambos os sexos, cursando entre primeiro e terceiro ano do ensino médio, pertencentes a uma escola da área de abrangência da Unidade de Saúde da Família, no centro de Porto Seguro.

O material discursivo foi registrado em diários de campo com relatos detalhados da oficina e posteriormente analisado utilizando a Análise de Conteúdo (AC). Segundo Bardin (2011) a AC pode ser definida como um conjunto de ferramentas metodológicas utilizadas para análise dos conteúdos e continentes dos discursos, o que permite ao pesquisador tanto o cálculo de frequência quanto a possibilidade de extrair dados passíveis de interpretação e construção de modelos. Segundo o autor, pode-se a partir, desses dados, construir-se uma hermenêutica baseada na dedução, na inferência.

A segunda fase do processo teve como objetivo identificar também as potencialidades locais e auxiliar a comunidade a compreender melhor a situação permitindo identificar os problemas e obstáculos que impedem seu desenvolvimento, proporcionando os elementos para priorização de seus problemas.

Os adolescentes apontaram diferentes tipos de violência, entre eles de gênero, violência institucional no atendimento ao usuário da Unidade de Saúde da Família, mas principalmente, em suas falas e dramatizações foram identificados problemas de violência urbana relacionada ao tráfico de drogas.

Nesta etapa de análise foi contundente a abordagem do grupo de adolescentes acerca do problema da violência no território. Estudo efetuado nas principais capitais do Brasil apontou que os estudantes da Educação Básica têm relacionado a violência, além de outros fatores, ao tráfico de drogas, provocando inquietação e insegurança nos adolescentes (Abramovay et al., 2016).

Todo este processo orientou o planejamento das ações da terceira fase do projeto, na qual foram realizadas oficinas de intervenção junto aos adolescentes, objetivando trabalhar a prevenção e redução de danos psicossociais relativos à violência no Território.

Finalmente, em função da proteção dos participantes não serão divulgados nesse relato o nome da escola nem da Unidade de Saúde, na qual foi realizado o trabalho. 


\section{Terceira fase}

\section{Colorindo o território: a expressão de sentimentos sem medo.}

A partir da priorização das questões relativas à violência no território foram planejadas quatro oficinas e rodas de conversa, realizadas em um Centro de Cultura, próximo à escola. As oficinas são uma estratégia válida nos processos de Pesquisa-Ação (Alberich Nistal, 2008) e eficazes para em processos de intervenção com adolescentes.

Vale lembrar que para cada oficina havia um coordenador dentre os acadêmicos participantes do PET Saúde e um relator, responsável pelo registro manual das discussões. O material produzido pelos adolescentes durante as oficinas foi recolhido por meio de um diário de campo. A descrição das mesmas será apresentada a seguir.

\section{Oficina 1 - Temática: Exclusão Social. Caracterização da Violência no Território.}

\section{Objetivos:}

Refletir sobre o território, os vínculos intersubjetivos e os afetos associados.

A dinâmica inicial foi o quebra-gelo da "Ilha". Para tal, foram espalhados jornais pelo salão e os estudantes deviam mover-se ao ritmo da música, e cessada esta, tomavam lugar em algum dos jornais espalhados. $\mathrm{Na}$ medida que os jornais eram retirados alguns participantes saiam da dinâmica não encontrando mais espaço para ocupar. Ao final foi realizada uma roda de conversa na qual refletiram sobre práticas de exclusão social experimentadas na sua cotidianidade e suas consequências subjetivas.

Após essa reflexão, foram convidados a colorirem um mapa do território do entorno da Escola com as cores verde, amarelo e vermelho segundo a segurança que sentiam em cada espaço, relatando o motivo dessa escolha. Ao descreverem o mapa identificaram os preconceitos sofridos por eles e por pessoas próximas, a violência relacionada ao domínio do território pelo tráfico de drogas e a ineficiência na segurança pública. 
Outros estudos também relatam a preocupação dos jovens em detalhar o entorno de suas escolas, descrevendo vários tipos de violências no cotidiano dos bairros em que vivem ou que transitam, o que, segundo o autor, indica que fogem da ideia reducionista de considerar a violência na escola como um produto acidental, desvinculado de violências estruturais que atingem alguns territórios ou que integram esses de forma desigual e perversa (Abramovay et al., 2016).

Vários dos membros do grupo se reconheceram na fala de um adolescente, que ao responder ao questionamento de como se sentiu diante da dinâmica da ilha, disse: "Matar para sobreviver, tem que matar pra sobreviver na ilha, né não?" A forma como os/as adolescentes percebem a si mesmos é construída socialmente em diálogo com as relações que estabelecem, tanto nas redes de apoio, como nos contextos caracterizados por conflitos, violências e desavenças, nos âmbitos privados e públicos (Zdebskyi et al., 2021). Nesse processo de construção da subjetividade os/as adolescentes reconhecem qual é seu papel em cada contexto de socialização. A frase destacada evidencia uma percepção da luta pela sobrevivência em um contexto hostil, competitivo e individualista; três características da sociedade contemporânea.

Abramovay et al. (2016) chama atenção para o fato de que a violência nas escolas por mais que amedronte e desestabilize os processos de ensino-aprendizagem, não pode ser sustentada pela indiferença e silêncio, e por mais que a vitimização e cumplicidade existam, deve-se problematizar e não culpabilizar, na busca de instrumentos coletivos de resolução dos problemas vividos.

Durante as discussões, temas como o sexismo, homofobia, precariedade do atendimento no Sistema Único de Saúde, justiça social, segurança pública também emergiram nas falas dos adolescentes, identificando núcleos de significação e conflito em torno de relações de gênero, assim como o reconhecimento de inequidades e desigualdade presentes na sua cotidianidade.

\section{Oficina 2 - Temática: Consenso grupal e Processos de Exclusão}

\section{Objetivos:}

Identificar os valores que determinam as relações interpessoais. Identificar laços de solidariedade. Refletir sobre a influência dos nossos conceitos, valores e como agimos diante de uma decisão de muitos riscos.

Para a abertura da oficina escolheu-se a dinâmica de "Duas Verdades e Uma Mentira" na qual a classe foi dividida em grupos e cada qual redigia três afirmações referentes aos componentes, sendo duas afirmações verdadeiras e uma falsa. Os outros grupos, após avaliação, tentaram identificar se verdade ou mentira. Houve discussão, e dificuldade de consenso. 
Na segunda parte da Oficina foi desenvolvida a Dinâmica do Abrigo Subterrâneo, com o objetivo refletir sobre resolução de conflitos e consenso. A dinâmica consistia em na escolha de 6 pessoas que poderiam sobreviver a uma hecatombe, dentre 12 com distintas características envolvendo preconceitos e tabus. O grupo deveria, junto com a escolha, apresentar a justificativa para tal.

Aconteceram pequenas discussões entre os adolescentes, respeitando as distintas falas. Percebeu-se grande incômodo pela necessidade de preterir um ou outro personagem. Emergiram falas como "foi horrivel ter que excluir"; "são vidas humanas e é difícil excluir", sentiram-se desconfortáveis, referindo, "como temos o direito de escolher?". (comunicação pessoal, 10 de outubro de 2017)

Emergiram também discordâncias acerca da escolha de pessoas com o critério de possibilidade de procriação e por isso, perpetuação da espécie. Uma adolescente, por ocasião da discussão final, argumentou "olha eu... eu tenho outra orientação sexual. Eu sou lésbica. Eu me permitiria procriar e não deixaria de ser lésbica". (comunicação pessoal, 10 de outubro de 2017)

Nesse sentido, (...)as normas vigentes em cada contexto social e a construção de gênero determinam, geralmente, as relações
afetivas e sexuais que se iniciam durante a adolescência, determinando também vulnerabilidades, com repercussões
a curto, médio e longo prazo. Essas mesmas normas sociais (...) influenciam as relações de poder estabelecidas entre
homens e mulheres. (Fonseca et al., 2018, p. 656)

Outra fala de um grupo de estudantes fez contraponto a essa discussão com o seguinte questionamento: "todo mundo pensando em procriação, que adianta criar gente sem cultura?" (comunicação pessoal, 10 de outubro de 2017) e que para criar uma sociedade dever-se-ia primeiro pensar no respeito pelo outro.

Algumas falas com conteúdo desqualificador sobre a personagem da prostituta e do usuário de drogas apareceram. Quando um dos grupos escolheu a prostituta justificando que ela era "nova", um aluno de outro grupo comenta "nova assim né... *risos *" (comunicação pessoal, 10 de outubro de 2017). Com relação ao usuário de drogas, o comentário foi que ele poderia ter um comportamento violento, uma associação comum em nossa sociedade, relacionada à representação social do usuário de drogas que os meios de comunicação frequentemente assumem como padrão.

Esta oficina confrontou os adolescentes com os critérios que usam para valorizar determinadas alteridades ou desprezar certas subjetividades que não fazem parte do universo social positivamente valorado. Ideais, valores, experiências pessoais e discursos dominantes fundamentam a construção de estereótipos e preconceitos a respeito de certos grupos sociais não reconhecidos. Frequentemente, são esses mesmos grupos e sujeitos aqueles tradicionalmente mais vulneráveis a diferentes tipos de violência e objeto de práticas de menosprezo motivadas por sua orientação sexual, raça, classe social, etc. (Honneth, 2010). 
Por esse motivo adolescentes que se identificam com subjetividades valorizadas negativamente podem ser mais vulneráveis a distintos tipos de violências, tanto na escola, como em outros contextos (Sousa et al., 2017) As/os participantes refletiram, a partir dessa atividade metafórica, como existem corpos "matáveis", muitas vezes eles mesmos, moradores de territorialidades periferizadas (Pereira Barros et al., 2021). Nesta oficina essa vulnerabilidade foi reconhecida e ao mesmo tempo questionada.

\section{Oficina 3 - Temática: Processos envolvendo escolhas pessoais.}

\section{Objetivos:}

Refletir sobre as relações de poder e o exercício de direitos no território.

Inicialmente foi realizado um jogo quebra-gelo conhecido como "Vivo ou Morto" com o propósito de focalizar os estudantes na atividade, diminuindo a dispersão. Nesta dinâmica, os adolescentes deveriam responder ao comando "vivo" permanecendo em pé e ao comando "morto", abaixando-se, aumentando gradativamente a dificuldade.

A Dinâmica seguinte foi a da Cesta, na qual foi aberta uma roda com todos sentados, e uma das monitoras passeava no interior da roda com uma cesta enfeitada, contendo diversos doces e guloseimas. A monitora oferecia para alguns, recusava a outros, escolhia alguns para compartilhar os doces no centro da roda e preteria outros adolescentes, sempre com uma postura convidativa.

Ao final a monitora se retirou e abriu-se a discussão. Os adolescentes se desapontam quando a monitora vai embora e brincam sobre fazer um motim para pegar seus doces, comentando que ela era uma e eles 20. Em contrapartida, um deles comenta "educação em primeiro lugar!" (comunicação pessoal, 17 de outubro de 2017), revelando a ideia de que uma rebelião está relacionada a falta de educação.

Foi perguntado como se sentiram, tanto aqueles que foram escolhidos quanto os preteridos. Uma adolescente que se sentou no meio da roda referiu que gostou, por ter se sentido especial; alguns referiram se sentir excluídos, "só por que sou preto", disse um, em tom de brincadeira; "Ela tirou paçoca do meu amiguinho e deu pra o moço ali" (comunicação pessoal, 17 de outubro de 2017) disse uma adolescente.

O grupo relacionou a dinâmica com amizades falsas, com preferências no emprego, com oferecimento de drogas, com ilusões em relações amorosas, e com a política, no sentido de que a população seria manipulada: "Esses políticos querendo fazer a gente de marionete"; "Sempre tem uma situação que a gente pode ser feito de marionete" (comunicação pessoal, 17 de outubro de 2017). 
Os adolescentes trouxeram relatos pessoais de como podem ser cativados pelas coisas "erradas" com o pensamento de que aquilo vai dar algum lucro. Um deles fez a reflexão de que a desigualdade social faz com que algo que era para ser de todos, acabe por ser destinado a alguns, como por exemplo a educação, e isso influencia nas escolhas da vida, inclusive relativamente às drogas.

Ao final da dinâmica foi lançado o questionamento de quais seriam os meios possíveis para protegê-los da entrada ao mundo das drogas e do tráfico. Em resposta emergiram falas como: "Família" referindo a pensar na família como fator de proteção que ela oferece por meio do apoio; e, em concordância outra adolescente afirma que "Muitas vezes eu precisei de mãe, do meu pai dizer que tá tudo bem". Uma adolescente discordou dizendo que "A família às vezes são os primeiros a falar que você não vai conseguir” (comunicação pessoal, 17 de outubro de 2017).

Uma adolescente referiu que "quando fazem essas escolhas muitas vezes as pessoas estão pensando na família" e outro, complementando diz "às vezes faz isso por precisão (necessidade)" (comunicação pessoal, 17 de outubro de 2017). Um adolescente referiu que o "Caráter" seria um fator de proteção, complementado pela fala de outro de que "Se eu aceitasse tudo aí, nem aqui mais eu tava (...) vai um tapinha aí, vamo fazer um assalto ali". Ainda no sentido que que se trata de uma escolha individual as falas "A gente vive todo dia com esse tipo de coisa"; "Tem gente fazendo coisa errada na escola, mas cada um com sua vida, cada um faz o que quer. Uma pessoa vai conseguir controlar um monte de aluno?". Um adolescente complementa, afirmando que "Não tem uma resposta certa pra falar como não entrar por esse caminho" (comunicação pessoal, 17 de outubro de 2017). Ao final, vários adolescentes afirmam que mais debates sobre abuso de álcool, drogas e a morte em decorrência do tráfico seria um meio interessante de diminuir os riscos.

Adicionalmente, Abramovay et al. (2016) aponta a necessidade de que a escola, seus dirigentes de forma geral, possam ouvir os estudantes, compreender suas críticas, crendo na ação comunicativa e na possibilidade de empreender mudanças de forma coletiva, participativa.

\section{Oficina 4 - Temática: Possibilidades positivas para o futuro}

\section{Objetivos:}

Identificar estratégias de proteção e autocuidado. Refletir sobre cenários possíveis de futuro. Identificar recursos sociais para a construção de estratégias de enfrentamento e diminuição de riscos. Avaliar as Oficinas vivenciadas. 
A oficina foi iniciada com uma dinâmica de sensibilização denominada "Frases de Futuro" na qual, ao som de uma música suave ao fundo, os adolescentes foram vendados e dispostos sentados em círculo. Após a organização, os monitores começam a leitura de reportagens sobre pessoas advindas de contextos sociais menos favorecidos que conseguiram posições de destaque seja nos esportes, na ciência, nas artes e outros, principalmente usando da educação como trampolim. Os adolescentes ao final foram convidados a experimentarem os obstáculos como desafios.

A segunda Dinâmica denominou-se Cartas para o Futuro, na qual foram convidados a escreverem uma carta para si mesmos. O objetivo era descrever os seus sonhos, desejos e projetos para esse ano. Em complementação à redação da carta, os adolescentes foram instruídos a escreverem uma lista de atividades e atitudes que tornariam possível a realização dos projetos, sonhos e desejos descritos na carta.

As cartas seriam guardadas todas juntas em lugar protegido, escolhido por eles, e em contrapartida, deveriam colocar em local visível a lista de atitudes, e, ao final deste ano, seriam abertas as cartas para se verificar quais projetos foram concretizados. Interessante que os adolescentes escolheram uma das monitoras como "guardiã" das cartas, a qual contou sua experiência pessoal de superação de uma situação de vulnerabilidade, o que, depreende-se, criou uma ponte afetiva entre os adolescentes e a mesma.

Para finalizar foi proposto um momento de compartilhamento das experiências por parte dos participantes em relação às dinâmicas do dia. Umas das alunas disse que não gostava muito do fato de ter que escrever para si mesma, assim como ter que planejar o que deverá ser feito ao longo do ano, porém, preferia que as "coisas acontecessem naturalmente". Um outro expôs seu alívio em escrever, porque "é sempre bom perceber suas capacidades" (comunicação pessoal, 24 de outubro de 2017). A adolescência é uma idade de contradições, e de acordo com Ribeiro do Valle e Marinho de Mattos (2011), o desenvolvimento social nos trouxe a possibilidade da conquista do próprio destino como direito de todas as pessoas sendo regido pela Educação, que se volta para a Saúde, de uma forma abrangente, sendo importante para o adolescente, o conhecimento e desenvolvimento de seu potencial, direção, respeito e oportunidade na própria sociedade.

Nas reflexões houve a percepção da expectativa ou da decepção, no sentido de visualizar o cumprimento ou não as propostas feitas na carta, relatadas pelas falas: "Particularmente, o engraçado é a gente ter dificuldade de falar da gente mesmo"; "Na escrita podemos colocar o sentimento para fora e isso é bom. Pois algumas pessoas não gostam de falar"; "Esperar algo de outra pessoa é muito mais fácil do que esperar de mim. Eu sei do que a outra pessoa é capaz de fazer."; "Incentivo até chegar onde quero"; "É legal quando a gente vê e traça uma meta"; "Para tudo o que vamos fazer, precisamos de um planejamento" (comunicação pessoal, 24 de outubro de 2017). Também foi mencionado que escrever é um incentivo; pois algumas vezes se almejamos alguma coisa, mas não estabelecemos metas é mais fácil de descumprir. 
No término dessa oficina abriu-se um espaço para avaliação geral, sendo solicitado aos adolescentes que descrevessem em uma palavra o que representou para eles essa experiência. As palavras foram - "Produtiva"; "Coisa positiva que nos faz abrir a mente"; "Escutar e conhecer a opinião dos outros (civilizadamente)"; "Cansativo"; "Prática de escutar, saber a opinião independente do certo e do errado"; "Muito boa"; "Legal, gostaria que tivesse mais vezes"; "Quero mais! Quando vai ter mais? Foram dinâmicas que atraíram a gente, e aprendemos a "visionar as coisas' com várias ideias, conhecimento a mais, de forma diferente. Vou sentir falta!"; "Quando é dinâmica e não palestra, nos interessamos muito mais. Conhecemos todos, mas na escola não interagimos assim."; "Foi foda"; "Muito legal! Deu uma vontade de levar isso para à escola"; "Achei muito legal, vocês deixam a gente muito à vontade para expressar o que sentimos sem medo das reações."; "Chega dar gostinho de chegar logo na faculdade."; "Bem legal, bem pensativo. A segunda oficina (a que teve a dinâmica do abrigo subterrâneo) foi a mais difícil ou a mais marcante."; "Aprendemos várias coisas com vocês também."; "Vocês são tão bons, que fizeram um colega nosso, que é muito tímido, falar."; "Bem interessante, é um conhecimento a mais"; "Foi top"; "Maravilhoso" (comunicação pessoal, 24 de outubro de 2017).

Os/as adolescentes avaliaram positivamente as oficinas, percebendo que as respostas são buscadas dentro de cada um, a partir da criação de um espaço aberto para poder se expressar sem medo de ser julgado. Alguns participantes sugeriram a ideia de aplicar esse método na escola, já que "palestras não funcionavam bem para alcançar as pessoas" (comunicação pessoal, 24 de outubro de 2017). Nesse sentido, a metodologia participativa proposta nesta experiência do PET-Saúde promove reflexão coletiva, autonomia e horizontalidade nas relações sociais e possui um potencial de transformação subjetiva, no diálogo com as alteridades, encontrado também em outras versões do PET-Saúde (Magnago et al., 2020).

Por fim, abriu-se espaço para que apontassem o que se poderia melhorar. Foram pontuados uma maior quantidade de vagas para a próxima vez e a inclusão de novos temas para as próximas oficinas, sendo eles: poluição, respeito às diferentes crenças e religiões, meio ambiente, orientação sexual, machismo/feminismo, preconceitos por ouvir determinados estilos musicais, política, homofobia.

A análise das percepções dos participantes sobre as ações realizadas no projeto e dos seus resultados, permitem concluir que a intervenção planejada facilitou a abordagem de temas centrais no processo de desenvolvimento psicológico dos adolescentes. Estas questões não estão vinculadas com o campo da saúde apenas por se relacionarem com a temática da violência como objeto de preocupação no campo da saúde coletiva, mas envolvem o campo da saúde mental orientada por uma definição que inclui as relações sociais e políticas que os sujeitos estabelecem. 
Adicionalmente, os problemas psicossociais interrompem o exercício dos laços sociais entre sujeitos e comunidades, indo além do campo das doenças mentais incluídas nos manuais diagnósticos e interrogam a capacidade da sociedade para reconhecer efetivamente os sujeitos que a constituem (Furtos \& Layal, 2005).

Neste sentido, as políticas de saúde mental na atenção básica devem estar orientadas a promover, manter e restaurar a capacidade de conviver entre os sujeitos, a qualificar a relação dos sujeitos consigo mesmos incluindo as possibilidades de criação de novas formas de ser e as produções subjetivas atípicas ou não normativas (Furtos e Layal, 2005). É neste sentido que o trabalho desenvolvido com os adolescentes pode estar localizado no campo da prevenção da violência e da promoção da saúde mental.

\section{Considerações Finais}

A consecução desse trabalho mostrou que a vivência de ações que favoreçam a interlocução entre o Ensino (Universidade), o Serviço (Atenção Básica) e a Comunidade (Escolas), alinhadas a metodologias participativas, configura-se como potente ferramenta de transformação social. A inserção dos estudantes universitários no PET-Saúde contribuiu para o conhecimento profundo sobre o Território, articulando conceitos abordados em sala de aula com a realidade concreta em contextos específicos.

Tendo como ponto de partida ações intersetoriais e interprofissionais, buscou-se a intersecção de saberes e práticas que trouxessem propostas de intervenção para a resolução de problemas no Território de Saúde, apontados como relevantes pelos diferentes atores envolvidos.

A escolha de estratégias como o Diagnóstico participativo, a partir do referencial da Pesquisa Ação Participante visou, entre outros aspectos aproximar os pesquisadores à realidade social, sem o viés da superioridade de saberes, entendendo que a resolução dos problemas passa pelo profundo conhecimento da comunidade a qual se busca atingir, além do processo de reflexão dessa coletividade sobre as suas potencialidades na resolução destes.

Nesta experiência de intervenção, a principal problemática trabalhada diz respeito à violência, que, por sua polissemia, tece uma gama de possibilidades de análise e intervenção, e para tanto, a interlocução entre a Saúde e as Ciências Sociais tornou-se um pano de fundo para discussões epistemológicas e metodológicas relevantes para o contexto. 
Os objetivos traçados a partir da análise do diagnóstico inicial experienciado, foram em sua maioria alcançados, desvelando outras problemáticas anteriormente invisíveis aos olhos dos pesquisadores, o que foi possível acontecer por meio da interação reflexiva entre pesquisadores e participantes da pesquisa, que na perspectiva da pesquisa-ação participante, tem sua intrínseca responsabilidade no levantamento e resolução dos problemas elencados.

No que diz respeito ao conhecimento do Território, suas características, relações e subjetividades, os participantes tornam-se atores principais à medida que compartilham seu olhar com os pesquisadores, devendo estes colocarem-se em posição de empatia e reconhecimento do saber e fazer do outro.

Dentro dos resultados do processo de Pesquisa-ação destacamos a capacidade dos adolescentes de identificar e refletir a respeito da sua posição subjetiva em relação distintas formas de violência, além daquelas mais estereotipadas no campo da violência urbana. Desta forma reconheceram práticas de exclusão social relacionadas ao exercício da sexualidade, às relações de gênero, e a privação de direitos, entre outras, como formas de violência presentes nas relações cotidianas que estabelecem nos distintos contextos de interação que os afetam do ponto de vista pessoal e social.

Foi de grande valia também a discussão sobre a potencialidade dos adolescentes em buscar opções no que tange à proteção e minimização de riscos relativos à violência no território, seja ela estrutural ou específica, reconhecendo as causas e as consequências da mesma, em sua vida em particular e na coletividade.

Esta experiência mostrou que os adolescentes não identificam dispositivos sociais nos quais essas reflexões possam ser realizadas em um contexto mais amplo, visando oferecer a escuta atenta e qualificada às suas demandas. Por esse motivo, a escola é um lugar privilegiado para a realização de intervenções orientadas à prevenção da violência contra crianças e adolescentes (Faraj et al., 2020; Vasconcelos et al., 2021). Tais ações podem integrar-se a estratégias e dispositivos como o PET-Saúde, com potencial de contribuição para a transformação e resolução de problemas concretos, a partir da participação direta das comunidades e do reconhecimento da autonomia dos atores sociais (e especificamente dos/as) jovens, em diálogo com profissionais de saúde, pesquisadores, estudantes em formação e docentes (Magnago et al., 2020).

Enfim, a experiência trouxe a possibilidade de transcender a Educação e a Saúde de forma abrangente, demonstrando que, a partir da reflexão sobre os problemas complexos como a violência, deve-se optar por uma visão ampliada, multidirecional e interdisciplinar, entendendo que nenhum campo de saber específico pode abarcar toda a multiplicidade de facetas e de possibilidades de compreensão e resolução. 


\section{Conflito de interesses}

Os autores declaram não haver conflito de interesses com instituição ou associação comercial de qualquer espécie.

\section{Referências}

Abramovay, M., García Castro, M., da Silva, P., \& Cerqueira, L. (2016). Diagnóstico participativo das violências nas escolas: falam os jovens (M. Abramovay, Coord.). FLACSO-Brasil, OEI, MEC.

Alberich Nistal, T. (2008). IAP, Redes y Mapas Sociales: Desde la Investigación a la Intervención Social. Portularia, VIII(1), 131-151. http://revista-redes.rediris.es/webredes/portularia/08. Tomas_Alberich_Nistal.pdf

Bardin, L. (2011). Análise de conteúdo. Edições 70.

Becker, D., Edmundo, K., Nunes, N. R., Bonatto, D., \& Souza, R. (2004) Empowerment e avaliação participativa em um programa de desenvolvimento local e promoção da saúde. Ciência \& Saúde Coletiva, 9(3), 655-667. https://doi.org/10.1590/S1413-81232004000300017

Presidência da República. Lei $N^{\circ}$ 8.080, (19 de setembro de 1990). Brasília: Dispõe sobre as condições para a promoção, proteção e recuperação da saúde, a organização e o funcionamento dos serviços correspondentes. http://www.planalto.gov.br/ccivil_03/leis/L8080.htm

Brasil. Ministério da Saúde. Portaria Interministerial $n^{\circ} 1.802$, (27 de agosto de 2008). Institui o Programa de Educação pelo Trabalho para a Saúde-PET-Saúde. Diário Oficial União. https://bvsms.saude.gov.br/bvs/saudelegis/gm/2008/pri1802_26_08_2008.html

Brasil. Diário Oficial União. (29 de setembro de 2015a) Edital No- 13,-Seleção para o Programa de Educação pelo Trabalho para a Saúde PET-SAÚDE/GRADUASUS-2016/2017- PET-Saúde. https://portalarquivos2.saude.gov.br/images/pdf/2015/setembro/29/Edital-PET-GraduaSUS.pdf

Brasil. Ministério da Saúde. (2015b). Asis-Análise de Situação de Saúde / Ministério da Saúde, Universidade Federal de Goiás. Ministério da Saúde, 3v.: il. 
Brasil. Presidência da República. Secretaria de Governo. (2017). Índice de vulnerabilidade juvenil à violência 2017: desigualdade racial, municípios com mais de 100 mil habitantes / Secretaria de Governo da Presidência da República, Secretaria Nacional de Juventude e Fórum Brasileiro de Segurança Pública. Fórum Brasileiro de Segurança Pública.

Buss, P. M. (2000). Promoção da saúde e qualidade de vida. Ciência \& Saúde Coletiva, 5(1), 163 177. https://doi.org/10.1590/S1413-81232000000100014

Cardoso Junior, J. C., \& Cunha, A. S. (Org.) (2015). Planejamento e avaliação de políticas públicas. Ipea. http://www.ipea.gov.br/agencia/images/stories/PDFs/livros/livros/livro_ppa_ vol_1_web.pdf

Castro, M. G., \& Abramovay M. (2015). Guia do diagnóstico participativo. FLACSO. http:// flacso.org.br/files/2015/08/Guia-do-Diagnostico-Participativo.pdf

De Santana Madruga, L. M., Queiroz Silva Ribeiro, K. S., Soares de Morais Freitas, C. H., de Almeida Becerra Pérez, I., Rodrigues Ribeiro Fernandes Pessoa, T., \& Guedes de Brito, G. E. (2015). O PET-Saúde da Família e a formação de profissionais da saúde: a percepção de estudantes. Interface-Comunicação, Saúde, Educação, 19(1), 805-816). https:// doi.org/10.1590/1807-57622014.0161

De Souza Minayo, M. C. Ramos de Souza, E., Alves da Silva, M. M., Gonçalves de Assis, S. (2018). Institucionalização do tema da violência no SUS: avanços e desafios. Ciência \& Saúde Coletiva,23(6), 2007-2016. https://doi.org/10.1590/1413-81232018236.04962018

Faraj, S. P., Beck Scott, J., \& Cardoso Siqueira, A. C. (2020). Escola como um espaço de prevenção da violência: um relato de experiência. Barbarói, Santa Cruz do Sul, (57), 254-273. http://dx.doi.org/10.17058/barbaroi.v0i57.11266

Faria, R. M., \& Bortolozzi, A. (2009). Espaço, território e saúde: contribuições de Milton Santos para o tema da Geografia da Saúde no Brasil. Revista Ra'e Ga. O Espaço Geográfico em Análise, 17, 31-41. http://dx.doi.org/10.5380/raega.v17i0.11995

Farias-Santos, B. C. S., \& Noro, L. R. A. (Março 2017). PET-Saúde como indutor da formação profissional para o Sistema Único de Saúde. Ciência \& Saúde Coletiva, 22(3), 997-1004. https://doi.org/10.1590/1413-81232017223.15822016

Fonseca, R. M. G. S., Santos, D. L. A., Gessner, R., Fornari, L. F., Oliveira, R. N. G., \& Schoenmaker, M. C. (2018). Gender, sexuality and violence: perception of mobilized adolescents in an online game. Revista Brasileira de Enfermagem,71(Suppl 1), 607-614. http://dx.doi. org/10.1590/0034-7167-2017-0561 
Furtos, J., \& Layal, C. (2005). La santé mentale en actes. De la clinique au politique. em Etudes, reserches, actions en santé mentale en Europe. Érès.Brasil Pereira, I., \& França Lima, J. C. (Org.) (2008). Dicionário da educação profissional em saúde (2a ed). Escola Politécnica de Saúde Joaquim Venáncio; Ministerio de Saúde. http://www.epsjv.fiocruz.br/upload/ ArtCient/25.pdf.

Ghiso, A. (1999). Acercamientos: el taller en procesos de investigación interactivos en Estudios sobre las Culturas Contemporáneas, V,(9), 141-153.

Honneth, A. (2010). Reconocimiento y Menosprecio. Sobre la fundamentación normativa de una teoria social. Katz.

Instituto de Pesquisa Econômica Aplicada e Fórum Brasileiro de Segurança Pública. (2018) Atlas da violência 2018. IPEA https://www.ipea.gov.br/portal/images/stories/PDFs/relatorio_institucional/180604_atlas_da_violencia_2018.pdf

Jorge, M. H. P. M. (2002). Violência como problema de saúde pública. Ciência e Cultura,54(1), 52-53. http://cienciaecultura.bvs.br/scielo.php?script=sci_arttext\&pid=S0009$67252002000100024 \& \operatorname{lng}=\mathrm{en} \& \mathrm{nrm}=\mathrm{iso}$

Kemmis, S., \& McTaggart, R. (2000). Participatory Action Research. En N. K. Denzin, S. Yvonna y Y. S. Lincoln(Eds), Handbook of Qualitative Research Participatory Action Research (pp. 567-605). Sage.

Magnago, C., França, T., Belisário, S. A., Dos Santos, M. R., \& Silva, C.B.G. (2020). O PETSaúde/GraduaSUS como mobilizador da integração inter, intra e extrainstitucional. En L. Janete, R. L. de Castro, Alves de Vilar e M. A. Dias (Org.), Educação e Trabalho: interface com a gestão em saúde (pp. 245-271). Natal: Uma. https://www.researchgate. net/publication/346287939_O_PET-SaudeGraduaSUS_como_mobilizador_da_integracao_inter_intra_e_extrainstitucional\#fullTextFileContent

Matus, C. (1993). Politica, planejamento e governo. IPEA.

Oliveira, C. C., Santini de Almeida, M. A., \& Morita, I. (2011). Violência e saúde: concepções de profissionais de uma Unidade Básica de Saúde. Revista Brasileira de Educação Médica,35(3), 412-420). https://doi.org/10.1590/S0100-55022011000300016

Organização Mundial da Saúde. (1995). Classificação Estatística Internacional de Doenças e Problemas relacionados à Saúde (10 Revisão). São Paulo, CBCD, EDUSP. 
Pereira Barros, J. P., Barboza da Silva, D. B., \& Barbosa Alencar, F. A. (2021). Maquinarias de guerra e mortes juvenis nas periferias do Ceará / War machines and juvenile deaths in the peripheries of Ceará. Revista De Psicologia, 12(1) 23-36. https://doi.org/10.36517/revpsiufc.12.1.2021.2

Santos, C., Pereira, K. W., \& Carlotto, M. S. (2010). Burnout em profissionais que trabalham no atendimento a vítimas de violência. Barbarói, (32), 69-81.

Santos, M. (1996). A natureza do espaço - Técnica e tempo. Razão e emoção. Hucitec.

Saquet, M. A., \& Silva, S. S. (2008). Milton Santos: concepções de geografia, espaço e território em Geo UERJ, 2(18), 24-42.

Seguridad Justicia y Paz. (1 de junio de 2020). Ranking 2019 de las 50 ciudades más violentas del mundo. http://seguridadjusticiaypaz.org.mx/sala-de-prensa/1590-boletin-ranking2019-de-las-50-ciudades-mas-violentas-del-mundo

Sousa, I. V., Brasil, C. C. P., da Silva, R. M., Vasconcelos, D. P., Silva, K. A., Bezerra I. N., \& Finan, T. J. (2017). Diagnóstico participativo para identificação de problemas de saúde em comunidade em situação de vulnerabilidade social. Ciência \& Saúde Coletiva, 22(12), 3945-3954.https://doi.org/10.1590/1413-812320172212.25012017

Souza Romeiro, J., Corrêa, M. M., Pazó, R., Leite, F. M. C., \& Cade, N. V. (2020). Violência física e fatores associados em participantes da Pesquisa Nacional de Saúde do Escolar (PeNSE). Ciência \& Saúde Coletiva, 26(02), 611-624. https://doi.org/10.1590/141381232021262.04552020

Spink, M. J., Menegon, V. M., \& Medrado, B. (2014). Oficinas como estratégia de pesquisa: articulações teórico-metodológicas e aplicações ético-políticas. Psicologia \& Sociedade, 26(1), 32-43. https://doi.org/10.1590/S0102-71822014000100005

Teixeira, C. (Org). (2010). Planejamento em saúde: conceitos, métodos e experiências. EDUFBA. http://www.saude.sp.gov.br/resources/ses/perfil/gestor/documentos-de-planejamento-emsaude/elaboracao-do-plano-estadual-de-saude-2010-2015/textos-de-apoios/livro_planejamento_em_saude_carmem_teixeira.pdf

Thiollent, J. M. M. (2000). Metodologia da Pesquisa-Ação. (Coleção temas básicos de pesquisaação). $10^{\mathrm{a}}$ ed. Cortez: Autores Associados

Universidade Federal do Sul da Bahia (UFSB). (2016). Relatório da Análise da Situação de Saúde do Território do Areião I-2016 - PET Saúde GraduaSUS. Equipe Saúde Coletiva. 
Ribeiro do Valle, L. E. L., \& Marinho de Mattos, M. J. (2011). Adolescência: as contradições da idade. Revista Psicopedagogia,28(87), 321-323.

Vasconcelos, M. I. O., Cavalcante, Y., Maciel, G., Vieira, M., Lopes, P., Farias, V., da Silva Junior, L., \& Ximenes Neto, F. (2021). Violência contra adolescentes e as estratégias de enfrentamento. Enfermagem em Foco, 11(5), 144-151. https://doi.org/10.21675/2357-707X.2020. v11.n5.3416

Waiselfiz, J. J. (2016). Mapa da Violência: Homicídios por Armas de Fogo no Brasil. FLACSO.

Zdebskyi, J. F., Máximo, C. E., Batista Pereira, U. T. (2021). Relações sociais e redes de apoio na adolescência: experiências \& mediadas pela música. Barbarói, (58), 8-29. http://dx.doi. org/10.17058/barbaroi.v0i58.4107 